Published in final edited form as:

Am J Psychiatry. 2004 October ; 161(10): 1790-1797.

\title{
Alcohol Dependence and Use of Treatment Services Among Women in the Community
}

\author{
Li-Tzy Wu, Sc.D. and Chris L. Ringwalt, Dr.P.H. \\ From RTI International; and the Pacific Institute for Research and Evaluation, Calverton, Md.
}

\section{Abstract}

Objective-This study examined the extent and characteristics of alcohol dependence and the perceived need for and use of alcohol treatment services among women compared with men in a nonclinical sample of adults 18-64 years of age.

Method-Data were drawn from the 1999 National Household Survey on Drug Abuse. The authors calculated rates and correlates of alcohol dependence and treatment among adult alcohol users in this sample.

Results-About 3\% of the women in the survey met criteria for DSM-IV alcohol dependence in the previous year. About 13\% of these women received alcohol treatment services in the same period. Only $8 \%$ of the women who did not receive treatment perceived a need for treatment. Younger women - those who were 18-25 years of age-were more likely to be dependent on alcohol but less likely to perceive a need for treatment or to use treatment services. Among alcohol-dependent women who received no treatment, those with a family income of $\$ 75,000$ or more, those who had two or more children living with them, and those who were not dependent on psychotherapeutic medications were less likely to perceive a need for help.

Conclusions-There were no significant differences between men and women in use of treatment services, location of services received, and perceived need for treatment. However, correlates of treatment service use varied somewhat by gender. These findings suggest that the goal of efforts to reduce barriers to alcohol treatment services should be to change people's attitudes toward alcohol abuse and seeking professional help.

Alcohol abuse and dependence are among the nation's most prevalent psychiatric diagnoses $(1,2)$. According to a report by the Centers for Disease Control and Prevention (3), approximately one in 30 women who knew they were pregnant reported risky drinking, and one in seven women of childbearing age who reported not being pregnant engaged in risky drinking (i.e., at least seven drinks per week or at least five drinks on any one occasion). Such patterns of alcohol use pose a serious threat to the developing fetus and may occur before a woman is aware that she is pregnant.

Alcohol abuse and dependence are highly comorbid with other psychiatric diagnoses $(1,4)$, especially among women $(4,5)$. Unfortunately, very few people with alcohol abuse or dependence receive substance abuse or mental health services $(6,7)$, and the use of such services is generally lower in this group than among those with almost any other psychiatric disorder (7-9). In particular, although female alcohol users appear to be more likely than male alcohol users to experience alcohol problems, they are less likely to use alcohol treatment services at

Address reprint requests to Dr. Wu, Center for Risk Behavior and Mental Health Research, RTI International, P.O. Box 12194, Research Triangle Park, NC 27709-2194; liwu@ rti.org (e-mail)..

Supported by National Institute on Alcohol Abuse and Alcoholism research grant R21 AA-013255. The Substance Abuse and Mental Health Data Archive (SAMHDA) and the Inter-University Consortium for Political and Social Research (ICPSR) are the providers of public use data files of the National Household Survey on Drug Abuse. 
substance abuse treatment facilities (10-12) or to enter treatment (13). Further, the length of time between the onset of drinking, the onset of problem drinking, and adverse health consequences is shorter among women than men (10).

Women often are underrepresented in studies of alcohol dependence and use of treatment services (10). In this study, we examine the extent and characteristics in men and women of 1) alcohol dependence, 2) use of treatment services, and 3) perceived need for alcohol treatment services within a nationally representative sample of noninstitutionalized adults 18-64 years of age.

\section{Method \\ Data Source}

Data were drawn from the public use file of the 1999 National Household Survey on Drug Abuse (14). This survey is designed to provide national estimates of the use of licit and illegal substances by Americans 12 years old or older. The target population included residents of households, shelters, rooming houses, and dormitories, as well as civilians living on military bases. To increase the accuracy of drug use estimates, young people 12-25 years of age were oversampled. Survey respondents were interviewed about their use of a variety of substances, problems related to substance use and dependence, use of substance abuse services, and demographic characteristics.

The 1999 National Household Survey on Drug Abuse data collection method involved inperson interviews at the respondent's place of residence and incorporated procedures developed to increase their cooperation and willingness to report drug use behavior honestly. These procedures combined computer-assisted personal interviews with audio computerassisted self-interviews, which were designed to provide a private, confidential setting for answering sensitive questions.

This study of secondary data analysis of existing files was declared exempt from review by the Research Triangle Institute Institutional Review Board.

\section{Study Sample}

Of the 32,628 adults 18-64 years of age who were interviewed, 17,379 (53\%) were women and $15,249(47 \%)$ were men. Alcohol use in the past year was reported by $12,146(70 \%)$ of the women and 11,754 (77\%) of the men $\left(\chi^{2}=89.89, \mathrm{df}=1, \mathrm{p}<0.001\right)$. Of the alcohol users, $40 \%$ were 18-34 years old, 9\% were African American, $10 \%$ were Hispanic, $4 \%$ were other minority groups, 55\% had at least some college education, $27 \%$ had never been married, and $42 \%$ had a family income of less than $\$ 40,000$ (weighted percents). There were slight gender variations in education (10\% of female alcohol users did not complete high school, compared with $14 \%$ of male users) and marital status ( $24 \%$ of female users had never been married, compared with $29 \%$ of male users).

\section{Definitions of Variables}

Alcohol dependence-The 1999 National Household Survey on Drug Abuse (14) included a series of questions to assess alcohol dependence in the past year based on seven DSM-IV criteria: 1) tolerance, 2) withdrawal, 3) inability to cut down or stop alcohol use, 4) spending a great deal of time obtaining or drinking alcohol or recovering from its effects, 5) reducing or giving up important activities because of alcohol use, 6) using alcohol more often than intended, and 7) having physical or psychological problems because of alcohol use. Respondents who met three or more of these criteria in the previous year were classified as alcohol dependent. 
Dependence on psychotherapeutic medication referred to dependence on any nonmedical use of prescription-type stimulants, sedatives, pain relievers, and tranquilizers, excluding over-thecounter drugs. Other illicit drug dependence referred to dependence on marijuana, cocaine, hallucinogens, heroin, or inhalants in the past year.

Treatment services-Use of alcohol treatment services was defined broadly as use in the past year of any service for alcohol-related problems at any location. We defined two types of treatment locations - specialty and nonspecialty—on the basis of respondents' answers to a question about the main place where they received their most recent treatment services. A specialty setting refers to residential alcohol/drug rehabilitation facilities, nonresidential alcohol/drug rehabilitation facilities or programs, and mental health facilities or centers. A nonspecialty setting includes private doctors' offices, hospitals, jails or prisons, courtsponsored programs, self-help groups, church-run programs, schools, workplaces, or community/city programs.

Perceived need for services-The subgroup of respondents who reported that they did not receive treatment or counseling for their alcohol use in the previous year were asked if they needed alcohol-related treatment or counseling during this period.

\section{Demographics}

We examined the following respondent characteristics: age, race/ethnicity, education, marital status, total family income, and population density of the area where the respondent lived (14). For the analysis of perceived need for alcohol treatment services and use of treatment services, we also determined how many children younger than 18 years of age were living with respondents because of the potential association with use of treatment services among women (15).

\section{Statistical Analyses}

The National Household Survey on Drug Abuse used a multistage probability sampling method to select participants. To ensure the representativeness of the sample, analysis weights were developed to adjust for variation in household selection, nonresponse, and poststratification of the selected sample to census data (16). Analyses were conducted with SUDAAN software to adjust for the National Household Survey on Drug Abuse's complex multistage survey design (17). All percentages reported in this paper are weighted estimates; sample sizes are unweighted.

We began by calculating the rates and correlates of alcohol dependence among alcohol users. Among the subset of respondents who were alcohol dependent, we determined the extent and correlates of their use of alcohol treatment services and, in those who did not use these services, their perceived need for treatment. We then conducted logistic regression procedures to identify 1) the characteristics of alcohol dependence, 2) correlates of use of alcohol treatment services, and 3) correlates of perceived need for such services. We used a stepwise method to select variables to be included in the final logistic regression model and determined their respective odds ratios. An adjusted odds ratio denotes the strength and direction of the association between a response variable (e.g., use of treatment services) and a given correlate, while controlling for other potentially confounding characteristics. An odds ratio greater than one indicates a positive association between the two variables; an odds ratio smaller than one denotes an inverse association. 


\section{Results}

\section{Descriptive Prevalence Estimates}

Of all adults 18-64 years old (unweighted $\mathrm{N}=32,628$ ), significantly fewer women than men met criteria for alcohol dependence in the previous year (Table 1). Among the subgroup of respondents who had used alcohol in the past year, women were significantly less likely than men to be classified as alcohol dependent (Table 1).

There was no difference between men and women in rate of comorbid drug dependence among alcohol-dependent adults (17\% for women versus $16 \%$ for men). Alcohol-dependent women and men were equally likely to meet criteria for dependence on psychotherapeutic medications (5\% of women and $2 \%$ of men) and other drugs ( $14 \%$ of women and $16 \%$ of men). Few alcoholdependent adults used alcohol treatment services (13\% of women and $12 \%$ of men). Of those who did not receive services, few perceived a need for treatment (8\% of women and $10 \%$ of men). None of these differences between men and women was statistically significant.

Many users of alcohol treatment services also received treatment for drug problems in the previous year. Of those using alcohol treatment services ( $\mathrm{N}=181), 42 \%$ of women and $51 \%$ of men reported using services for alcohol problems only. Alcohol-dependent women and men were equally likely to receive services at a specialty addiction/mental health treatment setting (6\% of women and $4 \%$ of men) or nonspecialty treatment location (7\% of women and $8 \%$ of men). We found similar results even when we restricted the specialty setting to substance abuse treatment facilities (4\% of women and 3\% of men) and compared it with all other nonsubstance-abuse treatment locations ( $8 \%$ of women and $9 \%$ of men).

\section{Correlates of Past-Year Alcohol Dependence}

We generated gender-specific logistic regression models to identify correlates of alcohol dependence among respondents who had used alcohol in the past year (Table 2). In our unadjusted analyses, age, education, marital status, family income, and drug dependence were each independently associated with alcohol dependence among female alcohol users. Even after we controlled for comorbid drug dependence, all variables remained significant. Female alcohol users 18-25 years old were twice as likely as female users 35-64 years old to be dependent on alcohol. Female alcohol users without a high school diploma (relative to college graduates), those who were white (relative to Hispanics), those with a family income of $\$ 75,000$ or more (relative to those with incomes of \$20,000-\$74,999), and those who never had been married were more likely to report alcohol dependence. In addition, dependence on psychotherapeutic medications was associated with a 16-fold increase in odds of alcohol dependence, and other illicit drug dependence was associated with a nine-fold increase.

Among male alcohol users, being white (relative to being African American), never having been married, having a family income of less than $\$ 20,000$, and dependence on psychotherapeutic medications and other drugs were associated with greater odds of alcohol dependence.

\section{Correlates of Using Alcohol Treatment Services}

The odds ratios for use of alcohol treatment services among alcohol-dependent adults are presented in Table 3. In the adjusted logistic regression, use of treatment services was associated with age, race/ethnicity, population density, and psychotherapeutic dependence. Women who were 18-25 years of age were less likely than women who were 35-64 years of age to receive services. African Americans (relative to whites), those living in metropolitan areas (relative to nonmetropolitan areas), and those with comorbid psychotherapeutic dependence were more likely to receive services. 
Except for age (like younger women, younger men were much less likely than those 35-64 years old to use services), correlates of use of treatment services among alcohol-dependent men were different from those of alcohol-dependent women. The men who had one child living with them were four times as likely as those without children to use services. Alcoholdependent men who also were dependent on illicit drugs were three times as likely as those without comorbid substance abuse to use services when their demographic characteristics were held constant.

To understand whether the use of alcohol treatment services varied by alcohol dependence symptoms (18), we used logistic regression analyses to examine their relationship. As shown in Table 4, after we held age, race/ethnicity, and education constant, tolerance, alcohol-related emotional or physical problems, and being unable to cut down on alcohol use increased the odds of using treatment services among women. For men, greater use of services was highly associated with alcohol-related emotional or physical problems but not with other symptoms.

\section{Correlates of Perceived Need for Alcohol Treatment Services}

Finally, we examined the characteristics associated with perceived need for alcohol treatment services among alcohol-dependent adults who did not use any alcohol treatment services in the previous year (Table 5). After holding comorbid drug dependence constant, we found that young women (those $18-25$ years of age), women with a family income of $\$ 75,000$ or more, and women who had two or more children living with them were less likely to report needing services. Alcohol-dependent women with comorbid psychotherapeutic dependence were seven times as likely as those without comorbid substance use to report needing services.

Among alcohol-dependent men who did not use any alcohol abuse service in the previous year, the perceived need for services was related to age but not to other characteristics examined. Even after holding comorbid drug dependence constant, we found that young men (those who were 18-25 years of age) were less likely than those who were 35-64 years old to report needing alcohol treatment.

\section{Discussion}

An estimated 3\% of all women and 6\% of all men in the 1999 National Household Survey on Drug Abuse met criteria for past-year alcohol dependence. Our prevalence estimates of alcohol dependence and use of treatment services are similar to those of other studies. Findings from the National Comorbidity Survey of subjects 15-54 years old (4) indicated that $2 \%$ of women and $7 \%$ of men met criteria for alcohol dependence in the previous year. The National Longitudinal Alcohol Epidemiologic Survey (6) found that 10\% of Americans 18 years old or older with alcohol abuse or dependence received alcohol treatment services in the previous year.

A remarkably high proportion of alcohol-dependent women as well as men did not use alcohol treatment services (6) and did not perceive a need for such services. Only two of 25 alcoholdependent women who did not receive services reported a need for help. The National Comorbidity Survey (19) also found that the proportion of people with a substance use disorder who reported a perceived need for help was low (14\%). These findings support other findings $(18,20)$ that there is a long lag time between the onset of alcohol problems and initial treatment contact with a health care provider (approximately a decade). Thus, many persons may not have sought help until their alcohol use resulted in substantial problems in their lives (20).

Many alcohol abusers do not seek treatment services because they do not perceive their drinking as a problem or because they prefer to handle it on their own $(21,22)$. Our study and others $(21,22)$ suggest that alcohol-dependent individuals may benefit from targeted educational 
interventions that increase their knowledge about the symptoms of alcohol abuse or dependence, its consequences, and the availability and effectiveness of treatment services.

Many people who use alcohol treatment services are seen in a nonaddiction treatment setting, which points to the vital role of general physicians and non-health-care agencies in the delivery of alcohol treatment services. However, substance abuse and/or mental health care provided by general medical providers or primary care physicians may be inadequate $(23,24)$. For instance, comorbid mood and anxiety disorders are more common among women with alcohol abuse or dependence than among their male counterparts $(4,5)$, but general medical providers may fail to adequately assess the possibility of comorbid mental health or substance abuse problems and non-health-care agencies may be unable to provide a full-scale psychiatric assessment (24).

Alcohol dependence among alcohol users was highly associated with drug dependence, particularly dependence on psychotherapeutic medications for women and other drug dependence for men. Among alcohol-dependent adults, use of treatment services was strongly related to comorbid dependence on psychotherapeutic medications in women and comorbid other drug dependence in men. These findings suggest that use of treatment services is determined by the severity of alcohol dependence and its immediate consequences (e.g., comorbid alcohol-related emotional/medical problems), which may prompt health care providers or others to notice them (25-27).

Women with alcohol problems are less likely than men to receive support from family or friends to enter treatment (28) and more likely to seek help in a nonaddiction treatment setting (11, 12). However, our findings suggest no significant gender differences in use of treatment services, receipt of services in a specialty treatment setting, and perceived needs for treatment. Weisner and Matzger (27) also found no gender difference in entry to alcohol/drug treatment. These findings may reflect a recent change in women's access to substance abuse care, perhaps caused by reductions in stigma, increased awareness of alcohol problems, or greater availability of women-focused treatment programs $(29,30)$.

For both genders, age is a significant correlate of use of treatment services and perceived need for treatment. Young adults are most likely to report a recent substance use disorder (2). Unfortunately, we found that young alcohol-dependent adults used fewer services and were less likely to perceive a need for services. Hajema et al. (31) also found that younger adults used fewer alcohol treatment services, independent of the severity of their alcohol problems. Heavy drinking among young adults may be more tolerated by peer groups and considered a transitional stage before the assumption of adult responsibilities (31). Young drinkers typically have a shorter duration of problem drinking than older drinkers and are more likely to claim that they can manage their drinking behavior without treatment.

We also found that African American alcohol-dependent women were more likely than their white counterparts to use treatment services (32) and that women with the highest income were less likely than those with lower incomes to perceive a need for help. Women in alcohol/drug treatment, especially African American women (33), tend to have lower incomes than men $(11,34)$. Yet African American women and those with lower incomes are least likely to complete treatment $(30,34)$. Entry into alcohol treatment may generate some personal and social losses because of stigma, separation from family, and negative job-related consequences (28). High-income women who do not seek alcohol treatment may deny their alcohol problems because of fear of stigma and other social losses but may seek other mental health services. In fact, socioeconomically disadvantaged people are most likely to enter public alcohol treatment programs, while higher-income people tend to enter private treatment sectors through workplace referrals (29). 
Although we did not observe any gender differences in the use of treatment services, women still may face unique psychosocial and program-related barriers to entering and remaining in treatment $(12,28,35,36)$. Men, especially married men, are more likely than women to receive support from family and friends to enter alcohol treatment (28). Women, especially those with children, experience more shame than men and worry about losing custody of their children and failing to fulfill childcare responsibilities when entering treatment (37-40). McMahon et al. (15) found a negative relationship between the number of children and the number of contacts for drug abuse treatment. We observed that alcohol-dependent women who had two or more children living with them were less likely to perceive a need for treatment than those without children. Available addiction treatment programs may not be designed to meet the special needs of women $(41,42)$. Women in substance abuse treatment typically view themselves as having a unique set of needs that tend to go unmet (41).

These findings should be interpreted with some caution. First, the annual National Household Survey on Drug Abuse uses a cross-sectional design and relies on respondents' self-reports. Our findings could be influenced by some memory and reporting biases. Nonetheless, the National Household Survey on Drug Abuse methodology has produced more valid estimates of substance use than telephone surveys (43). Further, studies have found self-reported substance use to be valid, especially among those with substance-related problems $(44,45)$. Second, the lack of available data on mental health problems, quality of care obtained, and DSM-IV criteria for alcohol abuse requires us to exclude these characteristics from our analyses.

It appears that only those individuals with the most severe alcohol and drug problems receive treatment or come to the attention of institutions or others that would facilitate their treatment entry (46). Young adults, white women, and those without comorbid drug dependence may underutilize alcohol treatment services and may be less likely to be identified by others as having alcohol problems. Barriers to use of treatment services and identification of alcohol problems deserve further investigation. For women who received services, the quality of the care received, the setting, and the level of appropriateness of their treatment deserve further examination.

\section{References}

1. Regier DA, Farmer ME, Rae DS, Locke BZ, Keith SJ, Judd LL, Goodwin FK. Comorbidity of mental disorders with alcohol and other drug abuse: results from the Epidemiologic Catchment Area (ECA) study. JAMA 1990;264:2511-2518. [PubMed: 2232018]

2. Kessler RC, McGonagle KA, Zhao S, Nelson CB, Hughes M, Eshleman S, Wittchen H-U, Kendler KS. Lifetime and 12-month prevalence of DSM-III-R psychiatric disorders in the United States: results from the National Comorbidity Survey. Arch Gen Psychiatry 1994;51:8-19. [PubMed: 8279933]

3. Centers for Disease Control and Prevention. Fetal Alcohol Syndrome. http://www.cdc.gov/ncbddd/ fas/

4. Kessler RC, Crum RM, Warner LA, Nelson CB, Schulenberg J, Anthony JC. Lifetime co-occurrence of DSM-III-R alcohol abuse and dependence with other psychiatric disorders in the National Comorbidity Survey. Arch Gen Psychiatry 1997;54:313-321. [PubMed: 9107147]

5. Ross HE. DSM-III-R alcohol abuse and dependence and psychiatric comorbidity in Ontario: results from the Mental Health Supplement to the Ontario Health Survey. Drug Alcohol Depend 1995;39:111128. [PubMed: 8529531]

6. Grant BF. The influence of comorbid major depression and substance use disorders on alcohol and drug treatment: results of a national survey. NIDA Res Monogr 1997;172:4-15. [PubMed: 9154262]

7. Kessler RC, Zhao S, Katz SJ, Kouzis AC, Frank RG, Edlund M, Leaf P. Past-year use of outpatient services for psychiatric problems in the National Comorbidity Survey. Am J Psychiatry 1999;156:115123. [PubMed: 9892306] 
8. Regier DA, Narrow WE, Rae DS, Manderscheid RW, Locke BZ, Goodwin FK. The de facto US mental and addictive disorders service system: Epidemiologic Catchment Area prospective 1-year prevalence rates of disorders and services. Arch Gen Psychiatry 1993;50:85-94. [PubMed: 8427558]

9. Bijl RV, Ravelli A. Psychiatric morbidity, service use, and need for care in the general population: results of the Netherlands Mental Health Survey and Incidence Study. Am J Public Health 2000;90:602-607. [PubMed: 10754976]

10. Greenfield SF. Women and alcohol use disorders. Harv Rev Psychiatry 2002;10:76-85. [PubMed: 11897748]

11. Weisner C, Schmidt L. Gender disparities in treatment for alcohol problems. JAMA 1992;268:18721876. [PubMed: 1328695]

12. Schober R, Annis HM. Barriers to help-seeking for change in drinking: a gender-focused review of the literature. Addict Behav 1996;21:81-92. [PubMed: 8729710]

13. Weisner C, Greenfield T, Room R. Trends in the treatment of alcohol problems in the US general population, 1979 through 1990. Am J Public Health 1995;85:55-60. [PubMed: 7832262]

14. Summary of Findings From the 1999 National Household Survey on Drug Abuse. Rockville, Md, Substance Abuse and Mental Health Services Administration, Office of Applied Studies, 2000

15. McMahon TJ, Winkel JD, Suchman NE, Luthar SS. Drug dependence, parenting responsibilities, and treatment history: why doesn't mom go for help? Drug Alcohol Depend 2002;65:105-114. [PubMed: 11772472]

16. Bowman KR, Penne MA, Chromy JR, Odom DM. 1999 National Household Survey on Drug Abuse, Sample Design Report. Rockville, Md, Substance Abuse and Mental Health Services Administration, Office of Applied Studies, 2001

17. Shah BV, Barnwell BG, Bieler GS. SUDAAN User's Manual, Release 7.5. Research Triangle Park, NC, Research Triangle Institute, 1997

18. Kessler RC, Aguilar-Gaxiola S, Berglund PA, Caraveo-Anduaga JJ, DeWit DJ, Greenfield SF, Kolody B, Olfson M, Vega WA. Patterns and predictors of treatment seeking after onset of a substance use disorder. Arch Gen Psychiatry 2001;58:1065-1071. [PubMed: 11695954]

19. Mojtabai R, Olfson M, Mechanic D. Perceived need and help-seeking in adults with mood, anxiety, or substance use disorders. Arch Gen Psychiatry 2002;59:77-84. [PubMed: 11779286]

20. Bucholz KK, Homan SM, Helzer JE. When do alcoholics first discuss drinking problems? J Stud Alcohol 1992;53:582-589. [PubMed: 1331614]

21. Cunningham JA, Sobell LC, Sobell MB, Agrawal S, Toneatto T. Barriers to treatment: why alcohol and drug abusers delay or never seek treatment. Addict Behav 1993;18:347-353. [PubMed: 8393611]

22. Grant BF. Barriers to alcoholism treatment: reasons for not seeking treatment in a general population sample. J Stud Alcohol 1997;58:365-371. [PubMed: 9203117]

23. Mechanic D. Treating mental illness: generalist versus specialist. Health Aff (Millwood) 1990;9:6175. [PubMed: 2289761]

24. Lehman AF. Heterogeneity of person and place: assessing co-occurring addictive and mental disorders. Am J Orthopsychiatry 1996;66:32-41. [PubMed: 8720639]

25. Booth BM, Kirchner J, Fortney J, Ross R, Rost K. Rural at-risk drinkers: correlates and one-year use of alcoholism treatment services. J Stud Alcohol 2000;61:267-277. [PubMed: 10757138]

26. Kirchner JE, Booth BM, Owen RR, Lancaster AE, Smith GR. Predictors of patient entry into alcohol treatment after initial diagnosis. J Behav Health Serv Res 2000;27:339-346. [PubMed: 10932447]

27. Weisner C, Matzger H. A prospective study of the factors influencing entry to alcohol and drug treatment. J Behav Health Serv Res 2002;29:126-137. [PubMed: 12032970]

28. Beckman LJ, Amaro H. Personal and social difficulties faced by women and men entering alcoholism treatment. J Stud Alcohol 1986;47:135-145. [PubMed: 3713175]

29. Weisner C, Schmidt LA. Rethinking access to alcohol treatment. Recent Dev Alcohol 2001;15:107136. [PubMed: 11449738]

30. Green CA, Polen MR, Dickinson DM, Lynch FL, Bennett MD. Gender differences in predictors of initiation, retention, and completion in an HMO-based substance abuse treatment program. J Subst Abuse Treat 2002;23:285-295. [PubMed: 12495790] 
31. Hajema KJ, Knibbe RA, Drop MJ. Social resources and alcohol-related losses as predictors of help seeking among male problem drinkers. J Stud Alcohol 1999;60:120-129. [PubMed: 10096317]

32. Jerrell JM, Wieduwilt KM, Macey DV. Use and costs of public-sector behavioral health services for African-American and white women. Psychiatr Serv 2002;53:195-200. [PubMed: 11821551]

33. Amaro H, Beckman LJ, Mays VM. A comparison of black and white women entering alcoholism treatment. J Stud Alcohol 1987;48:220-228. [PubMed: 3657163]

34. Mertens JR, Weisner CM. Predictors of substance abuse treatment retention among women and men in an HMO. Alcohol Clin Exp Res 2000;24:1525-1533. [PubMed: 11045861]

35. Mammo A, Weinbaum DF. Some factors that influence dropping out from outpatient alcoholism treatment facilities. J Stud Alcohol 1993;54:92-101. [PubMed: 8394958]

36. Quinby PM, Graham AV. Substance abuse among women. Prim Care 1993;20:131-140. [PubMed: 8464935]

37. Thom B. Sex differences in help-seeking for alcohol problems, 2: entry into treatment. Br J Addict 1987;82:989-997. [PubMed: 3479184]

38. Goldberg ME. Substance-abusing women: false stereotypes and real needs. Soc Work 1995;40:789798. [PubMed: 8629044]

39. Allen K. Barriers to treatment for addicted African-American women. J Natl Med Assoc 1995;87:751-756. [PubMed: 7473850]

40. Brienza RS, Stein MD. Alcohol use disorders in primary care: do gender-specific differences exist? J Gen Intern Med 2002;17:387-397. [PubMed: 12047738]

41. Nelson-Zlupko L, Dore MM, Kauffman E, Kaltenbach K. Women in recovery: their perceptions of treatment effectiveness. J Subst Abuse Treat 1996;13:51-59. [PubMed: 8699543]

42. Marsh JC, D’Aunno TA, Smith BD. Increasing access and providing social services to improve drug abuse treatment for women with children. Addiction 2000;95:1237-1247. [PubMed: 11092071]

43. Gfroerer JC, Hughes AL. Collecting data on illicit drug use by phone, in Survey Measurement of Drug Use: Methodological Studies: DHHS Publication ADM 92-1929. Edited by Turner CF, Lessler JT, Gfroerer JC. Rockville, Md, National Institute on Drug Abuse, 1992, pp 277-295

44. Brown J, Kranzler HR, Del Boca FK. Self-reports by alcohol and drug abuse inpatients: factors affecting reliability and validity. Br J Addict 1992;87:1013-1024. [PubMed: 1322747]

45. Colon HM, Robles RR, Sahai H. The validity of drug use self-reports among hard core drug users in a household survey in Puerto Rico: comparison of survey responses of cocaine and heroin use with hair tests. Drug Alcohol Depend 2002;67:269-279. [PubMed: 12127198]

46. Grella CE, Joshi V. Gender differences in drug treatment careers among clients in the national Drug Abuse Treatment Outcome Study. Am J Drug Alcohol Abuse 1999;25:385-406. [PubMed: 10473004] 
TABLE 1

Past-Year Rates of Alcohol Use, Alcohol Dependence, Perceived Need for Alcohol Treatment Services, and Use of Alcohol Treatment Services Among 18-64-Year-Old Adults in the 1999 National Household Survey on Drug Abuse

\begin{tabular}{|c|c|c|c|c|}
\hline \multirow[b]{2}{*}{ Alcohol Dependence Variable } & \multicolumn{2}{|c|}{ Women } & \multicolumn{2}{|c|}{ Men } \\
\hline & Rate & SE & Rate & SE \\
\hline Alcohol dependence among all adults $(\mathrm{N}=32,628)^{a}$ & 3.0 & 0.19 & 6.0 & 0.31 \\
\hline Alcohol dependence among all adults who used alcohol $(\mathrm{N}=23,900)^{b}$ & 4.6 & 0.28 & 8.0 & 0.41 \\
\hline $\begin{array}{l}\text { Use of alcohol treatment services among alcohol-dependent adults } \\
(\mathrm{N}=2,097)\end{array}$ & & & & \\
\hline Any treatment & 12.5 & 2.90 & 12.1 & 2.07 \\
\hline Treatment in specialty setting $c$ & 5.7 & 1.43 & 4.3 & 1.08 \\
\hline Treatment in nonspecialty setting $c$ & 6.8 & 2.64 & 7.7 & 1.84 \\
\hline $\begin{array}{l}\text { Perceived need for alcohol treatment services among alcohol-dependent } \\
\text { adults who did not receive any treatment services for alcohol-related } \\
\text { problems in the previous year }(\mathrm{N}=1,916)\end{array}$ & 7.7 & 2.11 & 10.3 & 1.72 \\
\hline
\end{tabular}

${ }^{a}$ Difference between men and women was significant $\left(\chi^{2}=68.85, \mathrm{df}=1, \mathrm{p}<0.001\right)$.

${ }^{b}$ Difference between men and women was significant $\left(\chi^{2}=47.95, \mathrm{df}=1, \mathrm{p}<0.001\right)$.

${ }^{c}$ Three respondents who did not report the location of services received were excluded from the analysis. 


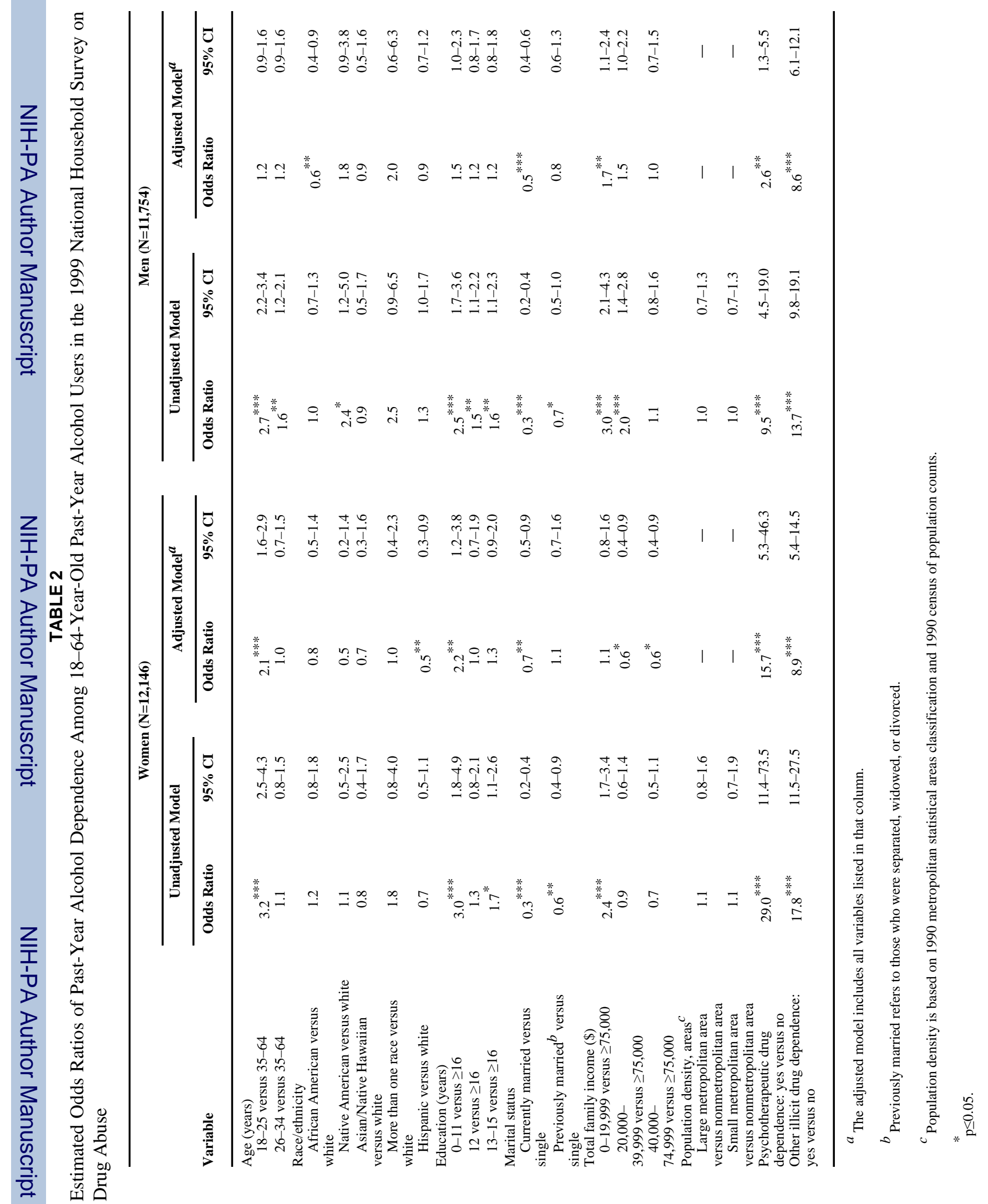




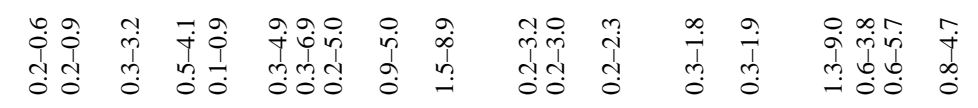

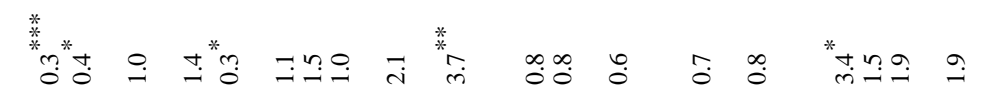

z

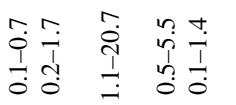

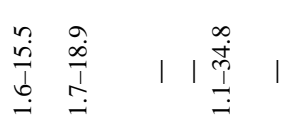

$>$ 荘

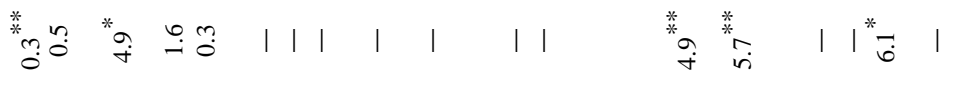


政

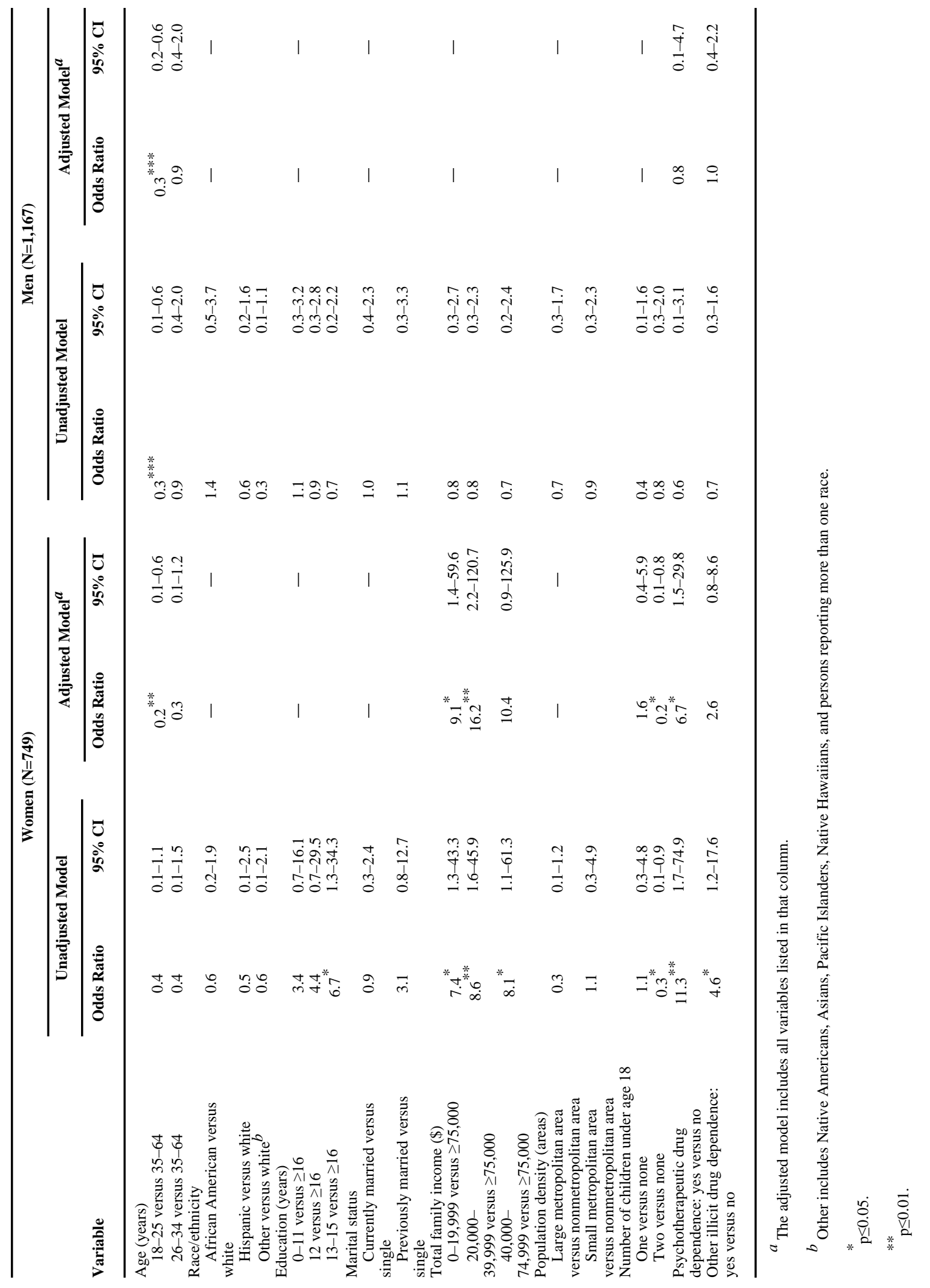

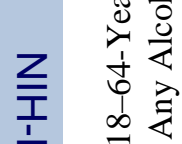

$>$ in

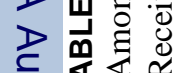

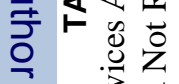

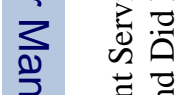


